\title{
Chronic nonbacterial osteomyelitis/Chronic recurrent multifocal osteomyelitis
}

INSERM

\section{Source}

INSERM. (1999). Orphanet: an online rare disease and orphan drug data base. Chronic nonbacterial osteomyelitis/Chronic recurrent multifocal osteomyelitis. ORPHA:324964

Chronic nonbacterial osteomyelitis (CNO), also known as chronic recurrent multifocal osteomyelitis (CRMO), is a chronic autoinflammatory syndrome that is characterized by multiple foci of painful swelling of bones, mainly in the metaphyses of the long bones, in addition to the pelvis, the shoulder girdle and the spine. 